\title{
FORMAÇÃO COM APERCEPÇÃO: AJUSTE E RESISTÊNCIA
}

\author{
Formation with apperception: \\ adjustment and resistance
}

Carlo Ralph De Musis ${ }^{1}$

\section{Resumo}

O objetivo deste ensaio é o de refletir sobre algumas implicações do pensamento desenvolvido por Theodor W. Adorno na educação. Com o aporte da noção Kantiana de juízo, este texto procura discutir a interface da educação com a indústria cultural, a sua viabilidade como instrumento do esclarecimento, e a sua articulação com o sensus communis.

Palavras-chave: Educação, Esclarecimento; Juízo.

\section{Abstract}

This study aims at reflecting on some implications of the thoughts developed by Theodor W. Adomo concerning education. With the contribution of Kantiniana's judgment notion this text tries to discuss the interface between education and cultural industry its viability as explanation instrument and its articulation with sensus communis.

Keywords: Education; Explanation; Judgment.

1 Doutorando em Educação: Psicologia da Educação, PUC-SP. demusis@uol.com.br 
O objetivo deste ensaio é o de refletir sobre algumas implicações do pensamento desenvolvido por Theodor W. Adorno na educação. Conforme Nicola Abbagnano (p. 305-306), o termo educação tradicionalmente se relaciona à divulgação, experiência e aperfeiçoamento de padrões de comportamento, crenças, conhecimentos e costumes que distinguem um grupo social. Podemos idealizar como finalidade da educação a formação de indivíduos capazes de desenvolver uma capacidade de apercepção ${ }^{2}$ crítica. A educação é objetivada como um meio facilitador do entendimento da realidade, ou seja, 0 esclarecimento pelo qual os indivíduos podem buscar a emancipação, tomando ciência dos limites de sua liberdade ao mesmo tempo em que, pela transcendência, os altera.

Um catalisador do esclarecimento é a assimilação do passado, e esta é uma das linhas expostas por Theodor Adorno no ensaio Educação após Auschwistz. O horror inerente ao campo de concentração nazista nos lembra de um evento que não deveria ter existido, representou o quanto nós podemos regredir e, por si só, nos faz recordar o significado, a importância de fatos que não podem ser esquecidos como eventos raros, acasos resultantes de um limite probabilístico. A educação deve ter a não ocorrência de fenômenos similares a Auschwistz como um de seus objetivos básicos, um parâmetro para que o seu absurdo não ocorra novamente. Nesta linha, seguindo o pensamento de Adorno, partimos para Auschwistz com o fim de entender como a sua referência negativa pode servir de subsídio para se pensar em educação.

Como foi possível tamanha barbárie?

A regressão aos instintos destrutivos experimentados em Auschwistz reforça, para Adorno, a tese Freudiana de que "a civilização, por seu turno, origina e fortalece progressivamente o que é anticivilizatório" (ADORNO, 1995). Temos hoje uma sociedade extremamente organizada a qual, para se substancializar reprime os instintos destrutivos, se utilizando, com protocolos e leis, de restrições para controlar a agressividade. Mas, com isso, acaba estimulando o próprio mal que combate. Este movimento configura uma espiral que tem como eixo o mal-estar do indivíduo e da civilização, da energia demandada surgem fenômenos como a violência que, com sua abrangência, desdobra-se em diversos níveis de apercepção: a violência em si, a banalização desta violência e a violência autopunitiva (induzida ao ego por meio de um super-ego rígido). A extensão deste fenômeno denuncia o quanto está imbricado na sociedade, alimentando-se das entranhas da civilização e carregando consigo a semente do retorno à barbárie.

2 O termo apercepção utiliza aqui o sentido, dado pela primeira vez por Leibniz, de consciência de suas percepções (ABBAGNANO, 2000, p. 71) 
Nesse sentido, Adomo chama atenção para a importância do estudo dos que deram forma ao nazismo, o estudo da personalidade dos carrascos nazistas. $\mathrm{O}$ seu entendimento pode esclarecer as condições objetivas que geraram o nazismo.

Freud (1997, p. 50) comenta que "o desenvolvimento da civilização impõe restrições a ela, e a justiça exige que ninguém fuja a estas restrições", sendo o "preço que pagamos por nosso avanço em termos de civilização é uma perda de felicidade pela intensificação de nosso sentimento de culpa" (FREUD, 1997, p. 97). Mas estes "velhos nazistas" estavam inseridos num Estado fundado em princípios criminosos, o desejo de progredir na comunidade, por fim, ajustava a consciência destes indivíduos com muita eficiência ${ }^{3}$. Subsidiada por uma configuração social e política permitia a legitimação do assassinato, a guerra deu à concepção do extermínio uma semblância de necessidade frente ao "problema judaico".

No desdobramento operacional da resolução desse "problema", Auschwistz foi concebido, não como primeira opção, exterminar surgiu como alternativa mais barata à deportação ${ }^{4}$. Mas matar com rapidez e economia não é simples, o desenvolvimento de câmaras de gás tinha em si o que havia de mais inovador em termos tecnológicos, da mesma forma foi necessário o suporte de uma ampla e complexa estrutura burocrática responsável por uma logística que ia da administração dos "conselhos judaicos", à captura, "expatriação"5 e encaminhamento dos judeus aos campos de extermínio.

A chamada "dureza necessária" foi muito utilizada pela propaganda nazista, esta frieza ampliou o alcance da violência física. A idéia de que "temos que ser duros para suportar a nossa terrível tarefa" colocava o extermínio como causa e fim de si mesmo. É importante comentar que a violência instaurada por este meio vai além do seu aspecto mais brutal, o físico, mas também se revela igualmente na indiferença frente ao observado.

A sociedade assimilou essa frieza como uma necessidade instrumental ditada pela guerra, se acostumando aos protocolos nazistas e, por fim, facilitando Auschwistz. A "solução final", mesmo com seu apelo gritante a barbárie, foi implementada com sucesso, os países disputavam qual estaria judenrein ${ }^{6}$ primeiro ${ }^{7}$. É assustador pensar em até onde a "solução final" teria chegado com os recursos técnicos disponíveis atualmente.

3 Nos diversos julgamentos promovidos após a guerra, os carrascos nazistas geralmente não apresentavam problemas com a sua consciência, apresentavam-se cientes do que tinham feito, mas atribuíam a culpa ao contexto (ARENDT, 2003).

4 Anterior à chamada "solução final" foi praticada a deportação dos judeus, as dificuldades e 0 custo de transporte exigiram a opção pelo extermínio (ARENDT, 2003).

5 Antes de serem mortos, os bens dos judeus eram inventariados e transferidos para o estado (ARENDT, 2003).

6 Sem judeus.

7 Existem exceções, principalmente na Finlândia e na Itália (ARENDT, 2003). 
Não foi a primeira vez na história da humanidade que se praticou o genocídio, mas a organização do extermínio com recursos e instrumentos típicos de engenharia de produção caracterizou um evento novo. Mas, mesmo sendo um fenômeno característico da sociedade moderna, podemos considerar Auschwistz como algo que ocorre de forma infreqüente?

Qualificar o evento como raro implica em o aceitar calcado em uma baixa probabilidade de ocorrência. Mas, aceitando esta conjectura não implica que as condições de ocorrência do evento sejam estocásticas, muito pelo contrário, são fortes e, muitas vezes, estruturadas a partir de gostos que penetram profundamente no cerne do indivíduo e da sociedade.

Entre os carrascos nazistas existia um prazer derivado da promoção do ato em si, uma satisfação calcada no instrumental, um aspecto que, voltando a Freud, nos leva a inferir que "os juízos de valor do homem acompanham diretamente os seus desejos de felicidade, e que, por conseguinte, constituem uma tentativa de apoiar com argumentos as suas ilusões" (FREUD, 1997, p. 111). Desenvolvendo um pouco mais a noção de juízo, podemos, em uma ótica Kantiana (1995), inferir que na compilação de seus juízos havia um gosto orientado por protocolos, em suma, se seguia os padrões pelo prazer inerente ao ato.

Os carrascos nazistas eram indivíduos incapazes de "visitar" os juízos alheios, são exemplos da uma ausência daquela "capacidade mental extra" que Kant indica como sensus communis, um senso de comunidade derivado da comparação dos nossos juízos com a "razão coletiva da humanidade". No nazismo, para se poder negar o direito de compartilhar a existência com os Judeus, foi necessário antes negar a possibilidade de identidades dos indivíduos externos ao grupo, foi preciso uma supressão da faculdade do juízo com base em princípios instrumentais. Esta necessidade instrumental pode ser justificada pela necessidade de manutenção da coesão dos grupos, conforme Freud esta se efetua na identificação recíproca dos membros por meio da adoção de um mesmo ideal de Eu.

Este narcisismo de grupo é estimulado ao custo de compensações materiais, estas "apoiadas e suplementadas" pelo extravasamento de "impulsos e instintos frustrados que carregam o latente 'descontentamento com a civilização'” (MARCUSE, 1999, p. 214). Segundo Herbert Marcuse:

Todas as gratificações vêm em conjunto com a emancipação da 'natureza' como oposta à civilização. É este apelo que as toma fermento da agressão e, ao mesmo tempo um paliativo para a submissão...O natural 'direito do corpo' supera o clamor do intelecto o qual ameaça penetrar a rede da 'comunidade popular' e descobrir sua fundamentação terrorista (MARCUSE, 1999, p. 214). 
No entanto, o processo de negação do outro não se circunscreve aos nazistas, mas, infelizmente, as razões particulares que falam pela possibilidade de repetição dos crimes cometidos pelos nazistas são ainda mais plausíveis. Elementos como a orientação cega do indivíduo por protocolos de conduta, uma certa "fúria organizacional" e graves limitações no exercício do pensamento crítico eram comuns aos nazistas e ainda são perceptíveis na sociedade moderna.

Em Auschwistz, tivemos um mecanismo com uma mescla entre ausência de reflexão e orientação cega a protocolos, hoje um movimento semelhante tende a se apresentar de forma mais sutil e eficiente. A observação do desenvolvimento da sociedade atual sugere que os homens, e todos os instrumentos derivados da sua condição humana, tendem a se assimilar sem o uso da faculdade do juízo, sem humanidade, coisificados. Tudo que cerca o homem vem se tornando extensão das mercadorias promovidas pela sociedade, as técnicas, os protocolos desenvolvidos têm sido propalados, e aceitos, intensivamente e sem apercepção.

Essa coisificação, segundo Adorno, é facilitada pela tendência que temos em formar grupos taxonômicos, conforme Freud, para um indivíduo num grupo:

Sua submissão se torna extraordinariamente intensificada, enquanto sua capacidade intelectual é acentuadamente reduzida, com ambos os processos se dirigindo para uma aproximação com os outros indivíduos do grupo; e esse resultado só pode ser alcançado pela remoção das inibições aos instintos que são peculiares a cada indivíduo, e pela resignação deste àquelas expressões de inclinações que são especialmente suas (FREUD, 1976, p. 99).

No grupo, o indivíduo reduz a sua consciência moral, enfraquecendo o seu eu pela adesão cega aos conhecimentos fornecidos pelo grupo. Freud comenta que

...o definhamento da personalidade individual consciente, a focalização de pensamentos e sentimentos em uma direção comum, a predominância do lado afetivo da mente e da vida psíquica inconsciente, a tendência à execução imediata das intenções tão logo ocorram: tudo isso corresponde a um estado de regressão a uma atividade mental primitiva, exatamente da espécie que estaríamos inclinados a atribuir a horda primeva (FREUD, 1976, p. 133).

Na essência do grupo está presente a horda primeva, a inserção ao grupo permite ao indivíduo esconder a fragilidade, mas o preço é uma regressão, o desenvolvimento de um realismo exarcebado, calcado na fetichização das técnicas enaltecidas pelo grupo e que, conseqüentemente, coisifica o percebido conforme os interesses do grupo. 
Conforme Adorno, a fragilidade se instala pela não consciência de nossos grilhões, não somos livres, temos a nossa autonomia cerceada pelos interesses dos grupos que nos instrumentalizam. Negando o refletir, o culto a estes conhecimentos introduz um viés que inviabiliza a emancipação, leva a um olhar que conduz a um arremedo de sensus communis, um sentido calcado apenas no compartilhar de protocolos e ideologias dominantes.

Neste contexto, a Indústria Cultural se apresenta como um grande "norteador" para os diversos aspectos da vita activa, suscitando aos nossos desejos individuais, oferecendo uma cultura de fácil digestão, uma semicultura destinada a divertir e a entreter, que empurra os indivíduos para o esquecimento histórico, massificação do gosto e triunfo do escapismo. Conforme Adorno:

Divertir-se significa estar de acordo. Isso só é possível se isso se isola do processo social em seu todo, se idiotiza e abandona desde 0 início a pretensão inescapável de toda obra, mesmo da mais insignificante, de refletir em sua limitação o todo. Divertir significa estar sempre: não ter que pensar nisso, esquecer o sofrimento até mesmo onde ele é mostrado. A impotência é sua própria base. É na verdade uma fuga, mas não, como afirma, uma fuga da realidade ruim, mas da última idéia de resistência que essa realidade ainda deixa subsistir (ADORNO, 1985, p. 135).

A Indústria Cultural induz desejos ao indivíduo, que passa a ser e se ver como consumidor se amalgamando à indústria. Embora este indivíduo, como parte de uma mescla, também influencie a Indústria Cultural, esta tem disponível para si técnicas baseadas em conhecimentos que possibilitam antever e controlar eventos de seu interesse.

O uso metódico destes conhecimentos permite uma otimização constante do ângulo de ataque da semicultura. A estatística e a programação linear, entre outros, se tornam instrumentos de dominação a serem aplicados num "universo de coisas". Um espaço que a semicultura se esforça por preencher integralmente, tornando-o virtualmente fechado, amorfo, excluindo o novo, 0 diferente, o criativo, o relativo à imaginação, à espontaneidade, à atividade intelectual. $\mathrm{O}$ que resta é a acomodação, a adaptação, a domesticação em que trabalho e ócio se coadunam para a reiteração do sistema vigente, para a perda da verossimilhança com o real.

Por fim, o indivíduo sofre um prejuízo na sua formação, se torna um semiformado. Sua limitada capacidade de apercepção o faz um indivíduo incompleto. Um eu fragilizado que satisfaz a sua libido nos grupos que, pelo apelo à sobrevivência do grupo, configuram um narcisismo coletivo o qual, por sua vez, estimula a demanda por mais semicultura. 
Temos então uma recursão, mas como sair dela?

Com este estado, o movimento de superação da contradição fica emperrado, mas o fato da sociedade industrial estimular a suspensão da dialética não implica que não existam contradições perceptíveis. Ao alimentar a consciência se potencializa a movimentação da sociedade, no sentido de superação da sua paralisia. Uma educação que denuncie os ditames da indústria cultural se faz necessária, ao efetuar a crítica, Adorno indica o ensejo de recuperação da razão emancipatória, do potencial crítico e, pela educação, fortalecer o sujeito, para resistir ao cerceamento conduzido pela barbárie e pela semicultura.

Estes limites só podem ser superados por uma faculdade de juízo abrangente e recursiva, um sentido que vá além da qualidade formal e avance para a emancipação do indivíduo. Para Adorno "a educação tem sentido unicamente como educação dirigida a uma auto-reflexão crítica" (ADORNO, 1995). Pelo exame dos conhecimentos, os dominados podem transpor a inércia inerente à semicultura e, por fim, buscar ações transformadoras que precipitem em autonomia. Uma concepção crítica da educação que pretenda ser emancipatória, e não apenas para a emancipação, deve obrigatoriamente ser autocrítica, deve ter como princípio o compromisso da escola na constituição de um sujeito reflexivo e, pelo desenvolvimento de sua capacidade de juízo, com potencial para o esclarecimento.

A educação se torna um refúgio em potencial contra a semiformação, mas, para ser real e efetiva, deve aspirar pela autonomia sem idealizar a escola desvinculada da sociedade onde ela está imersa, e a qual inevitavelmente se ajusta. Na arena entre 0 ajuste e a resistência a responsabilidade da educação se inicia na premência de se formar o indivíduo para a sociedade, mas deve se desenvolver para além destas demandas imediatas, deve conter em si uma crítica imanente e transcendente à sociedade. A educação assume um caráter dialético, onde é de sua responsabilidade inserir elementos depurativos na composição do indivíduo que o permitam transcender uma sociedade que a afeta, direta e indiretamente, como um todo.

A configuração histórica da escola é parâmetro para um esclarecimento que transcenda as suas limitações. Este movimento calca a recusa da ordem vigente e permite inserir na educação um olhar de resistência, chamando para si a denúncia do modus faciendi da Indústria cultural, formando os cidadãos para uma sociedade, mas sem levar a perda da originalidade dos indivíduos.

Por fim, podemos pensar no ato de educar como dialeticamente situada entre a regressão à barbárie e o esclarecimento. Para se educar é necessário ter ciência das limitações desta pretensão, o instrumental é componente da sociedade e, como tal, não pode ser rejeitado. O seu culto deriva de um prazer 
de fetiche, a esta sedução cabe a educação desenvolver no indivíduo a capacidade de resistir.

Mas será isto suficiente?

Talvez instigando no sentido de gosto dos indivíduos ${ }^{8}$ um prazer associado ao esclarecimento seja um meio de se sublimar instintos agressivos, é apenas uma conjectura, talvez a educação, com o fim aqui apresentado, leve a um reductio ad absurdum. Por fim, este ensaio finda deixando estas questões em aberto, mas confiando que a própria crítica carregue em si o potencial de sua superação. É apenas uma expectativa e, nesse sentido, fica aqui um desejo de, enfim, pensar educação como um espaço em que é possível colaborar na formação de indivíduos mais completos.

\section{Referências}

ABBAGNANO, NICOLA. Dicionário de filosofia. São Paulo, SP: Martins Fontes, 2000.

ADORNO, Theodor W. Teoría de la seudocultura. In: superstición. Madrid: Alianza, 1972. p.141-174.

. Filosofía y

ADORNO, Theodor W.; HORKHEIMER, Max. Dialética do esclarecimento: fragmentos filosóficos. Rio de Janeiro, RJ: Zahar, 1985.

ADORNO, TheodorW.; HORKHEIMER, Max. Educação após Auschwitz. Tradução de Wolfgang Leo Maar. Hipertexto disponível em: <http:// www.geocities.com/ filosofiasf/auschwitz.htm>. Acesso em: 05 nov. 2003.

ARENDT, HANNAH. Eichmann em Jerusalém: um relato sobre a banalidade do mal. São Paulo, SP: Companhia das Letras, 2003.

KANT, IMMANUEL Crítica da faculdade do juízo. Rio de Janeiro, RJ: Forense, 1995.

FREUD, SIGMUND. Psicologia de grupo e análise do ego (1921). Rio de Janeiro, RJ: Imago, 1976. (Standard Brasileira das Obras Completas de Sigmund Freud, v. 18).

FREUD, SIGMUND. O mal estar na civilização. Rio de Janeiro, RJ: Imago, 1997. MARCUSE, HERBERT. Tecnologia, guerra e fascismo. São Paulo, SP: Editora da Universidade Estadual de São Paulo, 1999.

Recebido em: 14 de novembro de 2005. Aceito em: 19 de dezembro de 2005.

8 Entende-se gosto no sentido Kantiano, associado à faculdade do juízo. 